\title{
Gymnastics: changing for the better?
}

Imagine an Olympic gymnast and you conjure up a picture of a small, slight child accomplishing dazzling feats on the vault, asymmetric bars, beam, or floor area. Now look back at the Atlanta Olympics. The same dazzling feats, but most of the gymnasts were no longer children. Yes, they were small and slight, but they had breasts and hips and waists. Female Olympic gymnastics has come full circle. Those of us who remember the beauty of Ludmila Tourischeva and Elvira Saadi will rejoice that the post-Korbut and Comaneci days of the pre-pubescent acrobat have once again been replaced by the flexibility and grace of the young woman. The governing body of the sport has changed the regulations for international competition, so that the gymnast has to have reached her 16th birthday in the year of the competition. These have to be forward steps, not just because of the aesthetics of one style of gymnastics versus another, but because of the implications for the physical and emotional health of the gymnasts.

This is not to be complacent-raising the age at which a gymnast can compete internationally will not automatically eliminate the physical and emotional problems associated with gymnastics. The sport of Olympic gymnastics tends to attract girls with personalities leading them to strive for perfection, with attention to detail and obsessive behaviour. ${ }^{1}$ These traits also occur in young women with eating disorders. Judges and coaches are extremely influential in imposing their views of what the ideal gymnast should look like either through oblique comments, or in the allocation of marks. The fact that many of the world's leading gymnasts have appeared to be pre-pubescent has meant that the pressures towards extreme weight control have proved overwhelming for some gymnasts in trying to emulate those they admire. Eating disorders in association with gymnastics, as well as other "feminine sports" have been recognised as part of the female athlete triad of amenorrhoea, eating disorder, and osteoporosis. ${ }^{2}$ Although the load-bearing dynamic exercise involved in gymnastics means that the resultant osteoporosis may be less than expected, ${ }^{3}$ coaches must acknowledge their responsibilities in recognising and dealing with eating disorders in gymnasts. The present change in female gymnastics represents a change of attitude towards the age and shape of gymnasts among coaches, judges, and competitors, and is to be welcomed.

Gymnastics, like any other sport pursued at a high level, is all-consuming. It requires a combination of ability, training, dedication, and perseverance. These qualities are admired in adult elite sportspersons, who are felt to be making their own choices, but engender concern when found in younger participants. In sports such as gymnastics where children may be training seriously at age 10 , and where previously elite competitors have retired before they reached their $20 \mathrm{~s}$, accusations of exploitation and abuse are raised. ${ }^{4}$ It is argued that children perform because of parental pressure and that their parents are indulging in "achievement by proxy", aware of the lucrative opportunities that success may bring. The sport attracts girls who both strive for perfection and tend to seek adult approval, but gymnastics is in essence an individual's sport. Although the girl may be competing for a team, she is the only person who dictates whether she performs well or badly. I argue that the sport allows the adolescent to develop identity and self worth in a way that does not represent the rebellion of youth and is approved of by her parents and coaches alike. ${ }^{5}$

It has been argued that parents abrogate adult responsibility in attributing a child's intensive training to her love of the sport. Many young gymnasts do love their sport, but they may also need help in maintaining a sense of perspective, rather than looking no further than the next competition. Parents and coaches need to exercise adult responsibility in ensuring that there is life outside and, more importantly, life after gymnastics. They have a responsibility to look beyond short term gain and not to ignore a gymnast's eating disorder, not to encourage her to compete whilst injured, and not to allow her to compromise her education by neglecting or even abandoning her schooling. Gymnastics may provide opportunities, particularly for self development and for travel and may bring lucrative opportunities for those who achieve at the highest level, but this is not the case for most gymnasts, particularly in the United Kingdom. The governing body of the sport also has a responsibility to young women leaving a sport that may have been a major part of their lives for some years. The USA Gymnastics Athlete Wellness Program has developed a mentoring scheme, pairing former gymnasts with currently competing elite gymnasts, to provide support for current competitors and a valuable role for the retired gymnast (Thies Marshall N, personal communication).

Gymnastics coaches argue that "Gymnastics is the only true sport, all the rest are Mickey Mouse games". It is certainly a sport that demands many qualities, such as strength, stamina, and fitness, but also flexibility, grace and, I would argue, physical and emotional maturity. It has been seen as a model for viewing worrying trends in competitive youth sports ${ }^{1}$; those worrying trends have not gone away, but perhaps improvement has begun.

Bristol Oncology Centre

KAREN FORBES

\section{Horfield Road, Bristol BS2 8ED}

1 Task Force on USA Gymnastics. Response to the female athlete triad. Technique $1994 ; 15: 18-22$.

2 Yeager KK, Agostini R, Nattiv A, Drinkwater B. The female athlete triad: disordered eating, amenorrhea, osteoporosis. Med Sci Sports Exerc 1993;25: 775-7.

3 Robinson TL, Snow-Harter C, Taaffe DR, Gillis D, Shaw J, Marcus R Gymnasts exhibit higher bone mass than runners despite similar prevalence of amenorrhea and oligomenorrhea. F Bone Min Res 1995;10:26-35.

4 Tofler IR, Stryer BK, Micheli LJ, Herman LR. Physical and emotional problems of elite female gymnasts. $N$ Engl F Med 1996;335:281-3.

5 Forbes $\mathrm{K}$. Physical and emotional problems of elite female gymnasts (letter). N Engl f Med 1997;336:14. 